\title{
SOBERANIA ALIMENTAR E ENERGÉTICA: A PROPOSIÇÃO CAMPONESA PARA UMA NOVA RELAÇÃO SOCIEDADE/NATUREZA
}

\section{Rodrigo Simão Camacho'}

Resumo: A problemática que envolve a Soberania Alimentar é um elemento fundamental que explicita a importância de nova forma de produção mais sustentável socioambientalmente. Nesse artigo estamos afirmando que os territórios camponeses se reproduzem por meio de uma produção diversificada e, por isso, estabelecem uma relação mais equilibrada com a natureza do que o modelo hegemônico que produz monocultura/commodities. Nessa perspectiva, temos o exemplo dos Movimentos dos Pequenos Agricultores (no Rio Grande do Sul) que atrela Soberania Alimentar e Soberania Energética como forma de resistência e recriação de seus territórios propondo uma forma de produção alternativa ao modelo do agronegócio.

Palavras-chave: Camponês. Sociedade/Natureza. Soberania Alimentar e Energética.

\section{INTRODUÇÃO}

A produção de commodities coloca em risco a Soberania Alimentar, pois, significa a substituição da produção de alimentos pela produção de monocultura de soja, eucalipto, cana etc. Por outro lado, a recriação camponesa, cujo modo de vida tem como cerne principal a produção de alimentos para a sobrevivência familiar, é a solução principal para a manutenção de a Soberania Alimentar. Logo, enquanto o agronegócio coloca em risco a Soberania Alimentar, a agricultura camponesa é a protagonista deste processo.

\footnotetext{
${ }^{1}$ Doutorando em Geografia pela FCT/UNESP - Presidente Prudente/SP. Membro do Grupo de pesquisa NERA. Email: rogeo@ymail.com.
} 


\section{Then Fórum Ambiental}

da Alta Paulista

ISSN 1980-0827

Volume 9, Número 10, 2013

Relações de Trabalho,

Produção e Ambiente

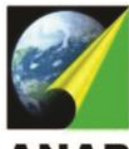

ANAP

Neste processo de recriação camponesa construída pelos movimentos socioterritoriais camponeses temos a experiência do Movimento de Pequenos Produtores - MPA. Estes visam construir uma produção autônoma do campesinato e romper com as relações capitalistas dominantes. A organização desse projeto se dá numa perspectiva de interação equilibrada entre a produção de alimentos e a produção de energia, projeto esse que o MPA denominou de ALIMERGIA, ou seja, combinando produção de alimentos e energia com proteção ao meio ambiente (alimento/meio ambiente/energia). Busca-se com este projeto a construção da Soberania Alimentar e a Soberania Energética concomitantemente. Esta experiência pode ser visualizada em um trabalho de campo feito em Frederico Westphalen/RS em 2010.

\section{1 - SOBERANIA ALIMENTAR VERSUS COMMODITIES}

A Soberania Alimentar está ligada a autonomia dos povos enquanto um direito que os mesmos têm de produzirem seus próprios alimentos em seus territórios.

É por esse referencial que se faz necessário discernirmos as diferenças entre segurança alimentar e soberania alimentar, antes que possíveis confusões possam ser construídas, pois quando apostamos na soberania alimentar não estamos apenas demarcando um campo de pesquisa ou mais uma nomenclatura para os próximos projetos, tampouco mais um conceito ou palavra chave. Então, para o momento é importante definir que enquanto a segurança alimentar tem a ver com a obrigação dos Estados nacionais em garantir o acesso aos alimentos em quantidades suficientes, sem se por em questão a origem dos mesmos, inclusive podendo contar com ajudas internacionais; a idéia e o conceito de Soberania Alimentar está erigido à partir da defesa do direito dos povos e dos países de definir suas próprias políticas e estratégias de produção de alimentos destinados ao abastecimento de sua população, antes mesmo da necessidade mercadológica e de exportação, como imperante e crescentemente marcado no cenário global (THOMAZ JR., 2007, p. 9, grifo nosso).

De acordo com João Pedro Stedile $(2012)^{2}$, as políticas de Segurança Alimentar dizem respeito a aplicação de recursos com o objetivo de que as pessoas não passem fome. São exemplos de políticas integrantes de a Segurança Alimentar: a merenda

\footnotetext{
${ }^{2}$ Informação verbal. Fala proferida durante o lançamento do livro: "Dicionário da Educação do Campo" que ocorreu no dia 10 de maio de 2012 na FCT/Unesp campus de Presidente Prudente.
} 
escolar, o bolsa família, a distribuição de cestas básicas etc. A Soberania Alimentar diz respeito ao conjunto de políticas que possibilitam o acesso das pessoas aos alimentos por meio de sua própria renda. No caso do campo, que os próprios povos possam produzir seus alimentos, no caso da cidade, que os trabalhadores possam ter acesso a alimentação por meio de sua própria renda.

Enquanto o agronegócio pode ser favorável a Segurança Alimentar, não tem como o mesmo apoiar a Soberania Alimentar, pois, sua lógica vai basicamente contra a reprodução da Soberania Alimentar. Para ser favorável a Soberania Alimentar o agronegócio teria que contrariar a sua própria essência. Dito de outra maneira:

Essa é uma questão que não tem como ser formulada desde o polo do capital (ser agenda do agronegócio) senão como farsa ou cinismo. Por isso também o capital pode admitir (em tempos de crise) discutir "segurança alimentar", mas não pode, sem trair a si mesmo, aceitar o debate acerca da "soberania alimentar" (pautado hoje pela agricultura camponesa). (CALDART et al., 2012, p. 15, grifo nosso).

A produção de alimentos deixa de ser algo para ser resolvido de maneira imediata e paliativa, para algo que tem a necessidade de transformar a estrutura de todo o modo de produção. Substituindo a lógica mercadológica do agronegócio e no lugar desenvolvendo uma lógica social de não só abastecimento de alimentos a população, mas também de controle dessa produção de alimentos de modo que possibilite 0 fortalecimento da agricultura camponesa. Assim, se torna uma questão de relevante importância para refletirmos é a Soberania Alimentar, ou seja, "a soberania alimentar é entendida como um princípio que define o direito e até o dever que cada povo tem de produzir os alimentos de que necessita para sua sobrevivência [...]". (STEDILE, 2007, p. 42). A soberania alimentar é uma alternativa para a segurança alimentar. As discussões de soberania alimentar devem estar situadas nos âmbitos das comunidades locais e regionais, comparando com o que se faz a nível global.

O debate de a Soberania Alimentar se mostra fundamental, principalmente na atualidade, em que começa a ficar mais rentável plantar para a produção de agrocombustíveis, ao invés de plantar para a produção de alimentos. Essa inversão de prioridades ocorre porque a produção agrícola para o capitalismo e, consequentemente, para o agronegócio, não passa de mais uma mercadoria, onde o alimento também se torna mercadoria, cuja produção depende do retorno financeiro que esse "negócio" dará. 
Porém, entendemos que a alimentação é a primeira necessidade humana, e, logo, é a primeira função do trabalho na transformação da natureza. Por isso, ela é a prioridade para os camponeses e todos os povos do campo, mas quando os camponeses são desterritorializados ocorre a perda da Soberania Alimentar.

Então, o que fundamenta a nossa visão de Soberania Alimentar voltada para o subsídio da agricultura camponesa é o próprio cenário brasileiro. Esse cenário reflete um país que busca concretizar as commodities, como a cana-de-açúcar e a soja, que estão em larga expansão no país. Podemos notar a expressão do debate que pretendemos levantar quando falamos da Soberania Alimentar como algo fundamental para soberania nacional, como podemos visualizar na Figura 1.

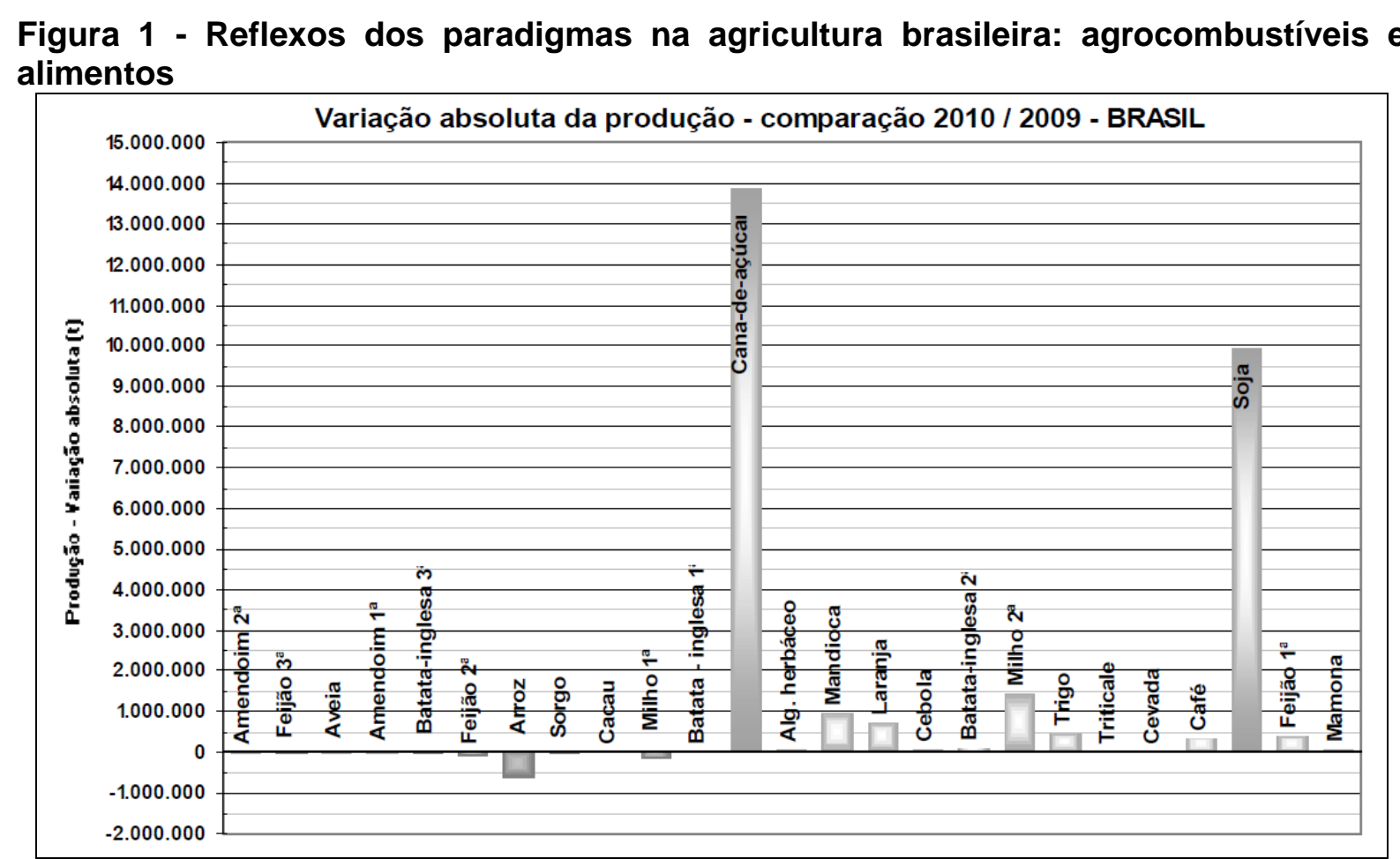

Fonte: IBGE, 2010.

A cana-de-açúcar (14 milhões de toneladas) e a soja (10 milhões de toneladas) são produtos de exportação e destaque de produção do agronegócio, em detrimento dos alimentos como o arroz, o feijão, o milho e a mandioca que estão numa amplitude de variação absoluta negativa para positiva com no máximo de 2 milhões de toneladas.

Portanto, entendemos que é a agricultura camponesa que deve ser a prioridade das políticas públicas e não o agronegócio. Corroborando com nossa análise, Stedile 
afirma: "o alimento é um direito de todos os seres humanos e não mera mercadoria da qual se busca extrair lucros [...]”. (2007: 42). Logo, a produção agrícola camponesa baseada na policultura, é essencial para manter a Soberania Alimentar.

A produção de alimentos é uma característica fundamental do modo de vida camponês (SHANIN, 1983). Para o camponês, a comida é o elemento central da produção e do consumo que são realizados na interdependência entre terra, família e trabalho, pois, expressa uma moral entre os homens e deles com a natureza. A troca e a reciprocidade entre os iguais divergem da lógica do negócio, da compra e venda do capitalismo (WOORTMANN, 1990).

A comida significa em primeiro lugar a reprodução material camponesa, todavia, sua importância ultrapassa a sua materialidade. A relação da comida, com a terra, 0 trabalho e a família é a seguinte: a comida é a fonte de reprodução familiar conseguida por meio do trabalho na terra. É por meio da produção de alimentos também, que se estabelecem laços de solidariedade e de sociabilidade com a comunidade. De uma maneira simbólica, ao oferecer os alimentos de sua produção a outros, se estabelecem vínculos com aqueles a quem considera (ALMEIDA; PAULINO, 2010).

Para pensarmos a produção camponesa, temos que pensar em primeiro lugar na produção da comida. Como relata Aloísio, militante do Movimento de Pequenos Agricultores, "[...] a gente tem produção de leite, frutas, café, mel de abelha, inserindo também agora peixe né, tamo querendo trabalhar com galinha caipira também, enfim, pra diversificar a renda da família e sair da lógica do monocultivo né”. (jul. 2010).

\section{2 - Alimergia: A pRoposição CAMPONESA PARA UMA NOVA RELAÇÃo SOCIEDADE/NATUREZA ATRAVÉS DA PRODUÇÃO DE ALIMENTOS E ENERGIA DE MANEIRA SUSTENTÁVEL}

"não podemos produzir em forma de monocultura de maneira nenhuma. $A$ diversidade da produção sempre foi esse legado histórico do camponês. Então, isso nós temos que manter". (ÊNIO, militante do MST, jul. 2010). 
Observando essa estrutura agrária-agrícola nacional, na visão do Paradigma da Questão Agrária, temos a situação/problema do campo brasileiro, e também a relação cidade-campo, dentro uma lógica estrutural. Partimos do princípio de que as relações sociais são mediadas pelo poder. Este poder pode ser do capital que cria e destrói os territórios, mas também temos a contradição dialética desse poder que está na (re)criação do território do não-capital, por exemplo, com a luta camponesa pela conquista de seus territórios. Dessa forma, a problemática central não está na conjuntura, ou nas relações camponesas, mas nas relações capitalistas que visam, fundamentalmente, 0 economicismo, ou seja, o crescimento econômico de uma minoria em detrimento de um planejamento territorial rural voltado para o desenvolvimento socioterritorial da maioria da população.

Após entendermos os novos fatores que compõem a questão agrária brasileira e as disputas territoriais que estão acontecendo na sua atualidade, refletimos acerca da importância de termos em mãos novos modos de recriar o espaço camponês, principalmente na condição em que as relações não capitalistas sejam recriadas no território. Então, fomos a campo a fim de estudarmos uma nova experiência articulada pelo MPA (Movimento dos Pequenos Agricultores), que traz a agroecologia e a soberania alimentar inerentes ao desenvolvimento territorial rural como pontos fundamentais para reprodução do território camponês.

O MPA é um movimento camponês, que tem um caráter popular e de massas. Sua base social é organizada em grupos de famílias nas comunidades camponesas. Esse movimento busca resgatar a identidade e a cultura camponesas na sua diversidade, dialogando com outros movimentos sociais em busca da construção de uma sociedade socialista (GÖRGEN, 2012).

O MPA é um movimento socioterritorial que surgiu do interior do MST, não como uma dissidência, mas como um movimento com características distintas, sendo os dois movimentos integrantes da Via Campesina. Enquanto o MST tem a função principal de destruir territórios capitalistas e construir novos territórios, o MPA tem a função de auxiliar na permanência do campesinato nos seus territórios evitando que sejam destruídos pelo capital. Partindo desse aspecto, poderíamos pressupor que são movimentos que tem em sua essência a composição organizacional semelhante, mas as estratégias de reprodução, de fato, são distintas, além de parte da estrutura desse movimento ser 
diferenciada. Observemos as diferentes estratégias de ação desses movimentos em que o território está situado na essência dessa luta.

Tanto o MST Nacional, quanto o MPA em Frederico Westphalen (FW), tem quatro pilares principais como base: organicidade (direção nacional e estadual), formação política (base), produção (organização produtiva) e a luta (manifestações e ocupações). É por meio desses quatro pilares fundamentais que se sustenta a lógica de atuação desses movimentos socioterritoriais. E, é por meio dessa lógica, que podemos observar, também, o território de atuação de cada um desses movimentos. A conquista de territórios, os assentamentos, é o principal alvo do MST. O MST, em síntese, parte de uma luta que se realiza por manifestações e ocupações com a intenção de pressionar o governo pela Reforma Agrária, ou seja, existe na sua essência uma busca pelo território (FERNANDES, 2000), além da perspectiva de ruptura com a lógica capitalista vigente.

A realidade da estrutura fundiária na região noroeste do Rio Grande do Sul - região de 63 municípios onde a Cooperbio (Cooperativa de Produção de Biocombustíveis) atua é baseada na pequena propriedade, como pode ser notada no Gráfico 3, onde as propriedades de 1 a 50 hectares representam, aproximadamente, 90\% dessa distribuição total de imóveis rurais.

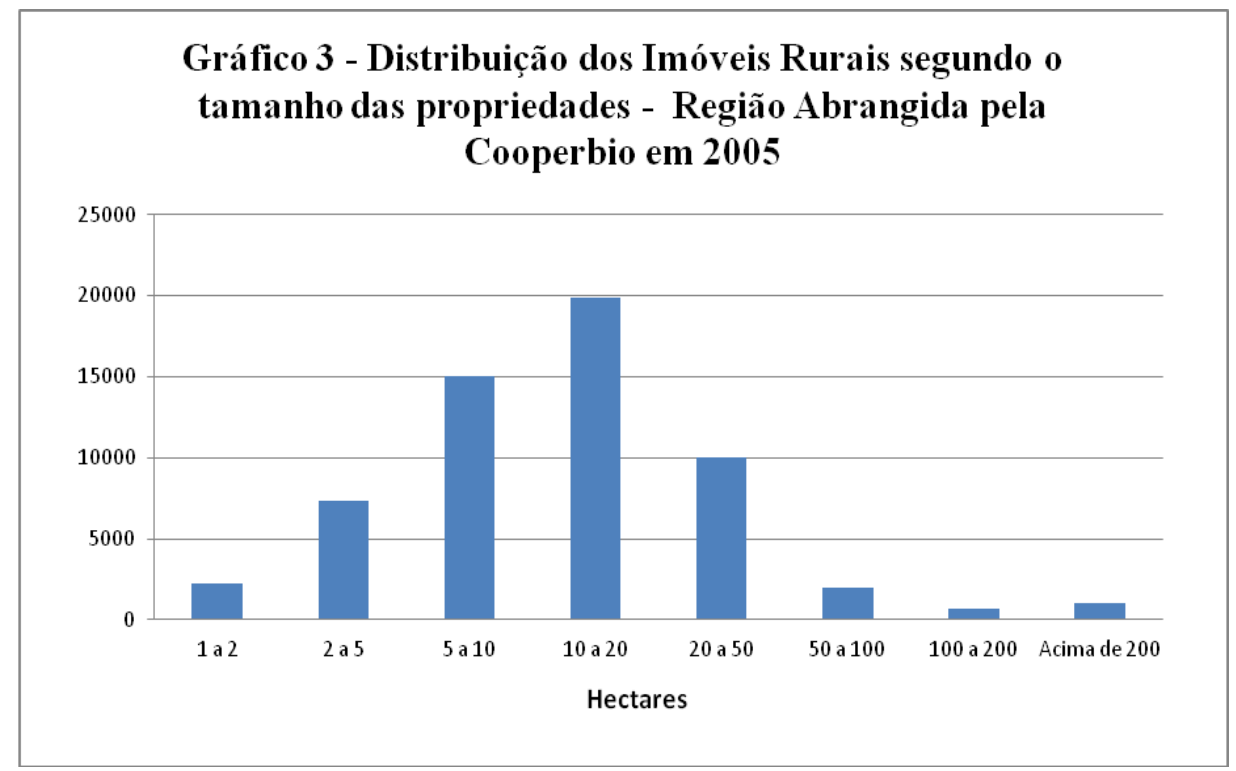

Fonte: IBGE, 2005. Org. MPA, 2007.

O processo de colonização que tivemos no Rio Grande do Sul, a partir das famílias de origem europeia, desemboca na divisão do território em pequenas propriedades na 
região noroeste do estado, e isso influenciou a construção de outro tipo de luta (LEAL, 2007). São 58 mil propriedades agrícolas com até 100 hectares, e essa configuração territorial se desdobra na luta na terra. A relação território-mercado está muito mais sensível nessa conjuntura, pois, as famílias já tem a terra e precisam de estratégias para garantir o uso e ocupação do seu território de forma digna e que permita continuidade da vida ali.

Essa luta está relacionada à resistência e manutenção da propriedade camponesa, com vistas à produção de Alimentos e Energia no território camponês. Mas, também aparece fortemente no âmbito imaterial do próprio território, que é a disputa por políticas públicas que viabilizem o Plano Camponês ${ }^{3}$. Além dessa disputa pelas políticas públicas, o MPA atua na tentativa de conscientizar essas famílias do processo destrutivo para o campesinato que é a reprodução da lógica capitalista, construindo outro modelo de produção para manter as características da pequena propriedade camponesa com objetivo focado para a Soberania Alimentar ${ }^{4}$. O Plano camponês está assentado em dois pilares fundamentais: o primeiro é a garantia das condições para se viver no campo e o segundo são as condições para produzir no campo:

O Plano Camponês tem dois pilares fundamentais: 1) condições para viver bem no campo (educação camponesa, moradia digna, espaços de esporte, lazer e cultura, saúde, vida em comunidade etc.); 2) condições para produzir comida saudável, respeitando a natureza, e para alimentar o povo trabalhador (crédito, assistência técnica, mecanização camponesa, sementes crioulas, comercialização, seguro agrícola, apoio para agroindústrias etc.). (GÖRGEN, 2012, p. 495).

Desse modo, "a produção de alimentos e culturas para produção de agrocombustíveis, de forma agroecológica, também é uma experiência em desenvolvimento pelo Movimento dos Pequenos Agricultores [...]" (FERNANDES; WELCH; GONÇALVES, 2011, p. 10). Para nomear essa experiência, o MPA criou um

\footnotetext{
${ }^{3}$ O projeto original é o "Plano Camponês de Desenvolvimento". Esse Projeto surgiu após um longo debate em Brasília, feito entre integrantes do MPA e estudiosos do tema que foi realizada entre 2004 e 2006. Desembocou num estudo sobre o campesinato no Brasil e um plano propositivo para o desenvolvimento territorial rural (um dos pontos principais para esse desenvolvimento era a Organização de Produção desvinculada da lógica do agronegócio).

${ }^{4}$ Esses dados são fruto: da reunião com Romário Rosseto, Marcelo e Débora, membros da Direção Nacional e Estadual do MPA, em Frederico Westphalen (RS), nos dias 23 e 26 de março de 2010; e do trabalho de campo nos dias 24 e 25 de março de 2010, nos municípios de Frederico Westphalen (RS) e Caiçara (RS), para observar a estrutura da CooperBio e essa nova experiência camponesa.
} 
termo: "ALIMERGIA". A partir desse paradigma, o movimento tem como principal meta: a produção de Alimentos e Energia, com Respeito ao Meio Ambiente, no interior do modo de produção camponês, entendendo o mesmo como uma célula, parte de um território, que tem relação com o todo (LEAL, 2007).

O plano camponês, baseado no conceito de ALIMERGIA, revoluciona com os pressupostos sociais vigentes no modo de produção e apropriação capitalista. A soberania alimentar passa a ser um conceito que participa concomitantemente com energia e reprodução do modo de vida camponês. Para esses camponeses, a soberania alimentar assevera que cada país tem o controle sobre o tipo de produção seja priorizada para sua população, de modo conjunto a produção agroecológica. É fundamental estabelecer a crítica na questão do desequilíbrio entre as necessidades da população e o que realmente se produz, onde se consome e quem ganha com essas amarras. Quando 45\% da produção global em 2012 foram desperdiçadas, o que precisamos não é produzir mais, mas distribuir melhor, direcionar recursos para alimentos, além de planejar de maneira mais eficaz (WITTMAN, 2011).

Métodos de produção sustentáveis e ecologicamente corretos, o movimento da soberania alimentar tem suscitado um interesse crescente em agroecologia, como uma abordagem multifuncional para produção de alimentos, que incorpora prestação sustento, conservação da biodiversidade e do ecossistema e do bem estar da comunidade. Com base na teoria da relação inversa entre o tamanho da propriedade e a produção agrícola total (Altieri 2009, 2010; Ishii-Eiteman 2009; Rosset 2008, 2009a), os proponentes da pequena escala no modelo de produção agroecológica de alimentos argumentam que a diversidade, aproveitamento social e ecológico pode levar a uma maior produtividade e resistência a vulnerabilidade socialecológica e às mudanças climáticas. [...] A agricultura multifuncional existe para produzir certos serviços ecológicos com mais eficiência do que os sistemas de monocultura. Além disso, um estudo importante por Badgley et al. (2007) mostrou que os métodos de produção agrícola orgânica, vem exigindo maiores entradas de trabalho para produção de alimentos suficientes para satisfazer as necessidades alimentares atuais sem expandir a terra agrícola. A recente da literatura sobre agroecologia e o direito à alimentação (Nações Unidas, 2010) sugere que os pequenos agricultores podem dobrar a produção de alimentos dentro de uma década em regiões críticas usando métodos de produção agroecológica e pesquisas de biodiversidade agrícola indicam que a base do conhecimento agricultor indígena contribui para a segurança alimentar. (p. 95).

O papel do camponês é fundamental na manutenção da vida do outro, porque ele produz para soberania alimentar e seu modo de vida produz equilíbrio social. Essa 
questão do desperdício levanta ao debate os aspectos relacionados à reordenação de hábitos alimentares; no que se refere aos aspectos nutritivos; a preservação cultural de produção e incorporação de novas técnicas; esquemas de circulação, fluxos e escoamento de produção e consumo; apropriação do produto pelo mercado; e especialmente, a reestruturação fundiária e de distribuição de riquezas e alimentos. "[...] A abordagem baseada em direitos que está incorporada na soberania alimentar é uma instituição explicitamente moral que está em contraste com os processos econômicos da globalização impulsionada pelo mercado" (WITTMAN, 2011, p. 92). Essa responsabilidade recai sobre o direito dos povos a construir, ou minimamente debater, as políticas públicas e fomentos necessários.

Frei Sergio Antonio Görgen explica que existe um antagonismo no campo com relação à produção de agrocombustíveis. Enquanto no agronegócio a produção de agrocombustíveis coloca em risco a Soberania Alimentar, pois, leva a uma competição entre a produção de alimentos e de agroenergia, a produção camponesa com seu projeto de alimergia combina produção de alimentos e energia com proteção ao meio ambiente, por meio de uma produção diversificada e consorciada. Em suas palavras:

No Brasil, há dois modelos antagônicos de produção de agrocombustíveis: 1) o do agronegócio, de produção em grande escala e com a terra organizada em latifúndios, concentrando riqueza, com cada vez maior controle das empresas transnacionais, com monoculturas de cana e soja, gerando pobreza e fome, sem sustentabilidade ambiental e criando uma competição inaceitável entre produção de alimentos e energia; 2) o da agricultura camponesa, voltado para a soberania alimentar e energética das comunidades camponesas, combinando produção de alimentos e energia com proteção ao meio ambiente (alimergia - alimento, meio ambiente, energia), com produção diversificada e consorciada e sistemas industriais de multifinalidades, de pequeno e médio porte, descentralizados. (2012, p. 54, grifo nosso).

A Alimergia é um novo conceito que implica na defesa simultânea da Soberania Alimentar e Energética a partir da formação de agroecossitemas complexos de maneira integrada e harmônica aos ecossistemas locais. Este conceito representa um novo paradigma necessário para responder as necessidades humanas alimentares e energéticas no período atual.

Alimergia é um novo conceito em agricultura, pecuária e floresta que procura desenvolver formatos produtivos que integrem, de maneira 
sinérgica, a produção de alimentos e de energia com a preservação ambiental. A alimergia visa à soberania alimentar e energética das comunidades e dos povos de maneira integrada e harmônica com os ecossistemas locais. [...]. Porém, a alimergia não é apenas um novo conceito que procura unir, em um processo produtivo integrado e sistêmico, alimentos, meio ambiente e energia. E um novo paradigma, necessário para responder aos desafios e às exigências objetivas que a comunidade humana e a sobrevivência da vida da biosfera colocam em termos energéticos, alimentares e ambientais para 0 presente e, dramaticamente, para a construção do futuro. (GÖRGEN, 2012, p. 54, grifo nosso).

A seguir observemos a Figura 2 que ilustra o que compreende a estrutura da Cooperbio e como se porta essa nova experiência camponesa de produção. Estrutura essa que é formada, e visualizada na Figura 3, por: Agrofloresta (interação floresta e culturas da alimergia), Floresta Energética (cultivo diversificado de culturas necessárias para a produção de energia que movimenta as micro destilarias), Micro-Destilarias e Produção agrícola diversificada (policultura). Formando assim, os agroecossitemas camponeses e a lógica camponesa de produção de alimentos e energia de forma integrada. A Cooperbio é responsável apenas pela produção e a CPC (Cooperativa de Produção Camponesa) realiza a parte de mercado.

Figura 2 - Comparação entre os modelos de Produção Tradicionais e a Cooperbio

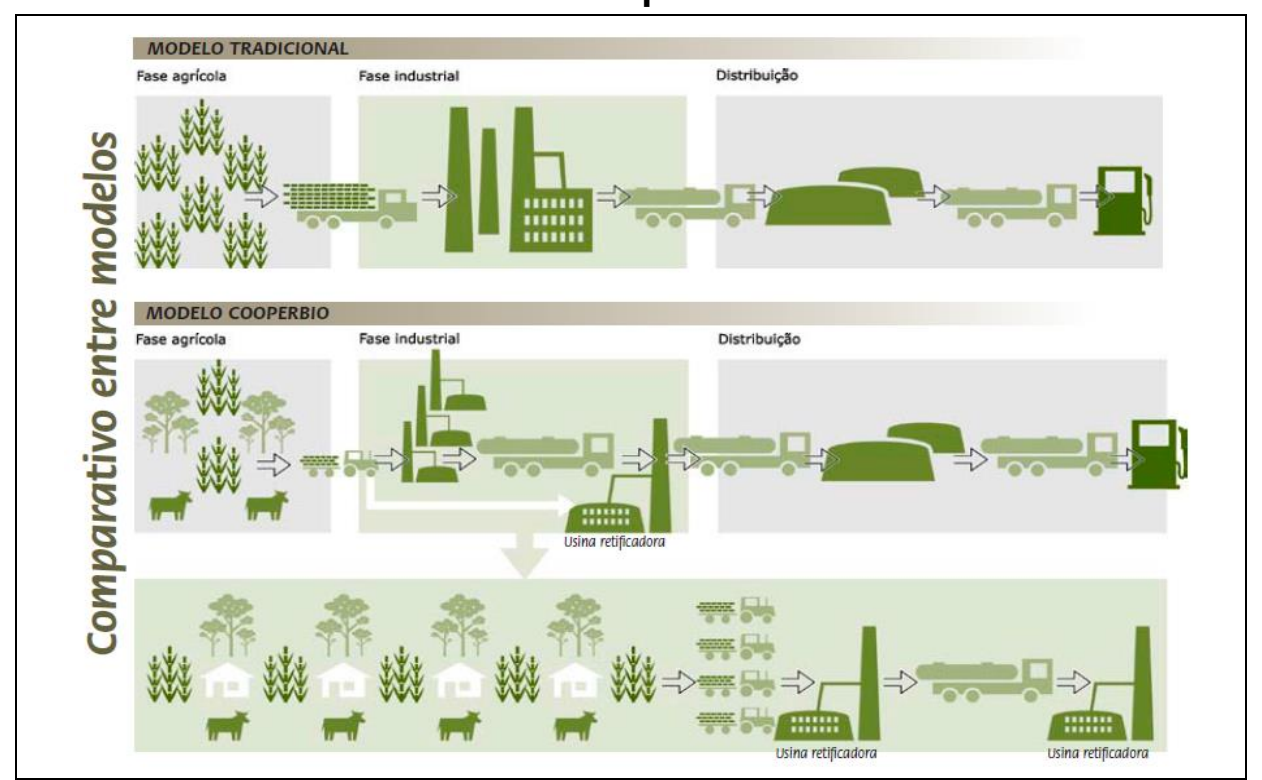

Fonte: MPA, 2007. 


\section{Figura 3 - Experiências da Produção Camponesa em Frederico Westphalen/RS e} Caiçara/RS

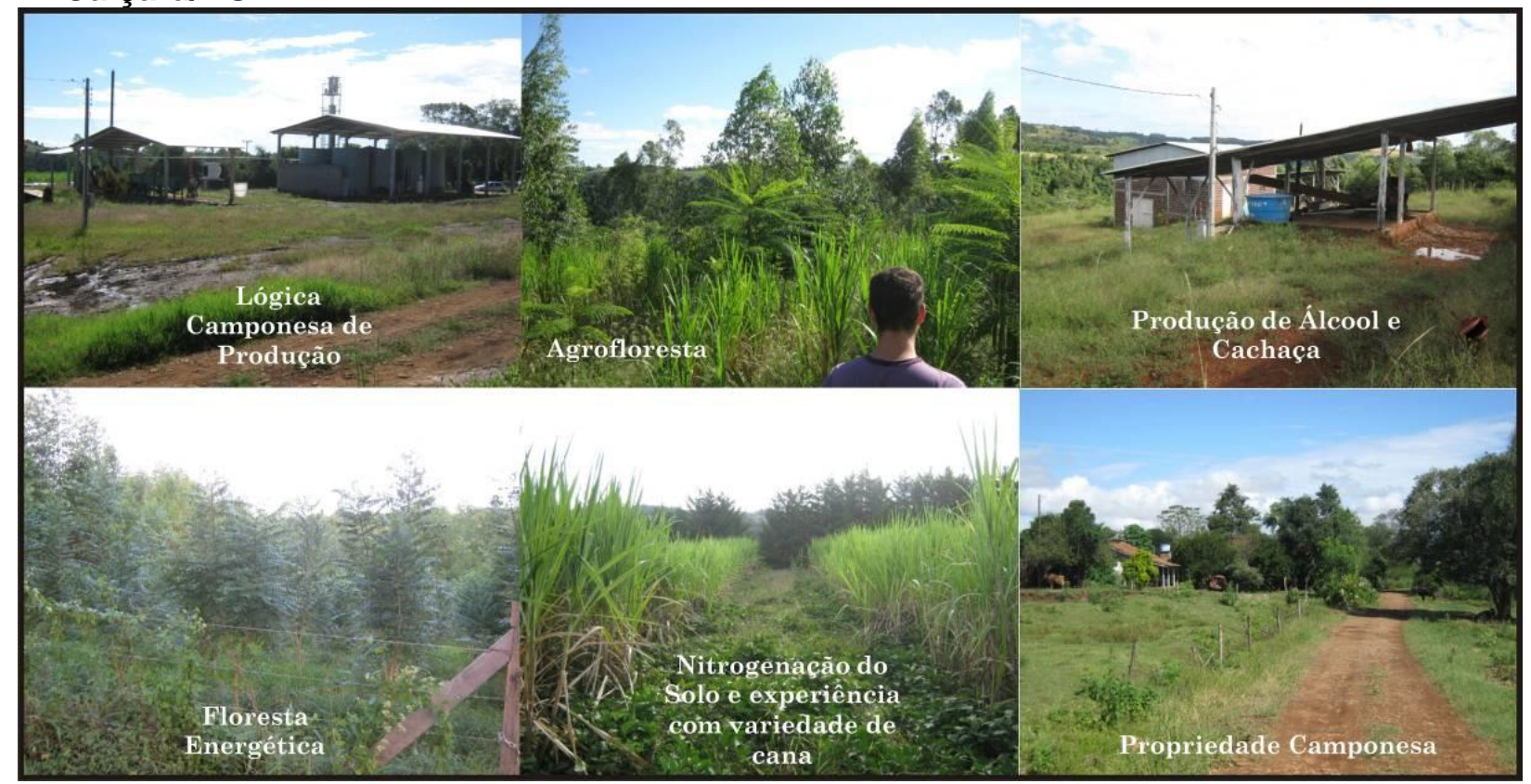

Fonte: Trabalho de Campo em Frederico Westphalen/RS e Caiçara/RS.

Org. Tiago E. A. Cubas.

As micro destilarias podem trabalhar com a produção diversificada e o manejo em forma de um ciclo que procura degradar menos possível a natureza, com alta taxa de renovabilidade. A produção pode ser voltada para a cana-de-açúcar, batata doce, mandioca e sorgo sacarino. Essas microdestilarias ainda são capazes de produzir açúcar mascavo, melado, rapadura, cachaça, ração animal, adubo orgânico e álcool. Trabalhando também com sistema de moenda móvel ou fixa.

A Cooperbio é composta por aproximadamente 800 famílias que, além disso, também compõem o MPA, que traz a discussão política e ideológica desse levante e manutenção do modo de produção camponês. Essa cooperativa, conjuntamente com o trabalho que o MPA faz nessa região do estado do $\mathrm{RS}$, tem desenvolvido um modelo agroecológico de produção. Modelo esse que tem como principais contribuições: 0 manejo sustentável do solo, a diversificação da matriz produtiva regional, o manejo de recursos naturais e uma agroindustrialização a favor da reprodução do território/territorialidade camponesa (LEAL, 2007). 


\section{CONSIDERAÇÕES FINAIS}

Neste artigo procuramos evidenciar a realidade concreta da construção do território camponês no exemplo frutífero da cooperativa criada pelo MPA (Movimento dos Pequenos Agricultores), em consonância com os pequenos produtores da região de Frederico Westphalen (Rio Grande do Sul - Brasil).

Os territórios camponeses são exemplos da recriação de relações sociais não capitalistas no capitalismo com base principal na produção de alimentos para o sustento da família e a venda do excedente para o restante da sociedade. Entendemos a agricultura camponesa como sendo a principal forma de garantir a Soberania Alimentar.

A Soberania Alimentar e a Soberania Energética são propostas defendidas por um movimento socioterritorial camponês ligado a Via campesina, o MPA. Esse exemplo demonstra a atitude propositiva dos movimentos camponeses. Não basta defendermos a destruição das relações capitalistas e a territorialização do agronegócio no campo, é necessário propor um modelo alternativo a esse modelo que entendemos ser pautado na exploração insaciável do ser humano e da natureza.

\section{REFERÊNCIAS}

ALMEIDA, Rosemeire Aparecida de. (Re) criação do campesinato, identidade e distinção: a luta pela terra e o habitus de classe. São Paulo: UNESP, 2006.

O conceito de classe camponesa em questão. Revista Terra Livre, São Paulo: AGB, ano 19, v. 2, n.21, p. 73-88, jul./dez. 2003.

; PAULINO, Eliane Tomiasi. Fundamentos teóricos para o entendimento da questão agrária: breves considerações. Revista Geografia, Londrina, v.9, n.2, p. 113127, jul./dez. 2000.

; PAULINO, Eliane Tomiasi. Terra e território: a questão camponesa no capitalismo. São Paulo: Expressão Popular, 2010.

CALDART, Roseli Salete; PEREIRA, Isabel Brasil; ALENTEJANO, Paulo; FRIGOTTO, Gaudêncio (Orgs.). Apresentação. In: Dicionário da Educação do Campo. Rio de Janeiro: Escola Politécnica de Saúde Joaquim Venâncio; São Paulo: Expressão Popular, 2012. p. 3-21. 
CHAYANOV, Alexander V. La Organización de la Unidad Económica Campesina. Buenos Aires: Ediciones Nueva Visión, 1974.

FERNANDES, Bernardo Mançano. A ocupação como forma de acesso à terra. In: . A formação do MST no Brasil. Petrópolis: Vozes, 2000. p. 279-301.

Movimentos socioterritoriais e movimentos socioespaciais: contribuição teórica para uma leitura geográfica dos movimentos sociais. Revista Nera, Presidente Prudente: Unesp, ano 8, n. 6, p. 14 - 34, jan./jun. 2005.

Questão agrária, pesquisa e MST. São Paulo: Cortez, 2001. (Questões da Nossa época, 92).

. Questão Agrária: conflitualidade e desenvolvimento territorial. In: BUAINAIN, Antônio Márcio (org). Luta pela terra, reforma agrária e gestão de conflitos no Brasil. Campinas: Editora da Unicamp, 2008a. p.173-230.

. Entrando nos territórios do território. Presidente Prudente: Boletim DATALUTA (março), 2008b.

. Conflitualidade e desenvolvimento territorial. In: Luta pela Terra, Reforma Agrária e Gestão de Conflitos no Brasil. Campinas: Editora Unicamp, 2008c.

Sobre a tipologia de territórios. In: SAQUET, Aurélio Marcos; SPOSITO, Eliseu Savério (org). Territórios e territorialidades: teorias, processos e conflitos, p. 197-215. São Paulo: Expressão Popular, 2009.

Soberania Alimentar como Território. Presidente Prudente: [s.n], 2010.

; MOLINA, Mônica Castagna. O campo da educação do campo. In: MOLINA, Mônica Castagna; JESUS, Sonia Meire Santos Azevedo de. (Org). Por uma educação do campo: contribuições para a construção de um projeto de educação do campo. Brasília: Articulação Nacional "Por Uma Educação do Campo", 2004, p. 53-91. (Por Uma Educação do Campo, 5).

; WELCH, Clifford Andrew; GONÇALVES, Elienai Constantino. Políticas de agrocombustíveis no Brasil: paradigmas e disputa territorial. [S.I.: s.n.], 2011/prelo.

GÖRGEN, Frei Sergio Antonio. Agrocombustíveis. In: CALDART, Roseli Salete; PEREIRA, Isabel Brasil; ALENTEJANO, Paulo; FRIGOTTO, Gaudêncio (Orgs.). 
Dicionário da Educação do Campo. Rio de Janeiro: Escola Politécnica de Saúde Joaquim Venâncio; São Paulo: Expressão Popular, 2012. p. 51-57.

. Movimento dos Pequenos Agricultores (MPA). In: CALDART, Roseli Salete; PEREIRA, Isabel Brasil; ALENTEJANO, Paulo; FRIGOTTO, Gaudêncio (Orgs.). Dicionário da Educação do Campo. Rio de Janeiro: Escola Politécnica de Saúde Joaquim Venâncio; São Paulo: Expressão Popular, 2012. p. 492-497.

LEAL, Marcelo. Cooperbio. Uma Cooperativa do Movimento dos Pequenos Agricultores. In: ORTIZ, Lúcia Schild. Construindo a Soberania Energética e Alimentar. Porto Alegre: Núcleo Amigos da Terra/Brasil, 2007.

LEFEBVRE, Henri. The Production of Space. New York: Oxford University Press, 1991.

MARTINS, José de Souza. Os camponeses e a política no Brasil. Petrópolis: Vozes, 1981.

MCMICHAEL, Philip. A food regime genealogy. London: Journal of Peasant Studies, p.139-169, vol. 36, 2009.

MAPA (Ministério da Agricultura, Pecuária e Abastecimento). Disponível em: <http://www.agricultura.gov.br/>. Acesso em 18 nov. 2011.

MDA (Ministério do Desenvolvimento Agrário). Disponível em: <http://www.mda.gov.br/portal/>. Acesso em 18 nov. 2011.

OLIVEIRA, Ariovaldo U. de. A agricultura camponesa no Brasil. 3. ed. São Paulo: Contexto, 1997.

A geografia agrária e as transformações territoriais recentes no campo brasileiro. In: CARLOS, Ana F. A. (Org.). Novos caminhos da geografia. São Paulo: Contexto, 1999. p. 63-137.

As relações de produção na agricultura sob o capitalismo. In: Modo capitalista de produção e agricultura. São Paulo: Ática, 1986. p. 61-78.

Geografia agrária: perspectivas no início do século XXI. In: OLIVEIRA, Ariovaldo U. de; MARQUES, Marta Inês Medeiros (Org.). O campo no século XXI: território de vida, de luta e de construção da justiça social. São Paulo: Casa amarela; Paz e Terra, 2004. p. 27-64. 
PAULINO, Eliane Tomiasi. A diversidade das lutas na luta pela terra. In: Revista eletrônica da Associação dos Geógrafos Brasileiros: seção Três Lagoas, Três Lagoas, v. 1, ano 3, p.28-47, nov. 2006.

QUIJANO, Escobar. El laberinto de America Latina: hay otras salidas?. De Econ. Y Ciencias Sociales. 2004.

RAFFESTIN, Claude. Por uma geografia do poder. São Paulo: Ática, 1993.

SHANIN, Teodor. La Classe Incomoda: Sociología política del campesinato en una sociedad em desarrollo (Rússia 1910-1925). Vérsion Española de Fernando Andrada Tápia. Madri: Alianza Editorial, 1983.

STEDILE, João Pedro. O MST e a questão agrária. Estudos Avanzados. Vol. 11, n. 31, p. 69-97. 1997.

STEDILE, João Pedro. Soberania alimentar, o que é isso? Revista Caros Amigos, São Paulo: Casa Amarela, ano 10, n. 120, p. 42, mar. 2007.

TERRITÓRIOS DA CIDADANIA. Disponível em: <http://www.territoriosdacidadania.gov.br/>. Acesso em 18 nov. 2011.

THOMAZ JR., Antônio. Trabalho, Reforma Agrária e Soberania Alimentar (Em Questão a Classe Trabalhadora e a Luta de Classes no Brasil). Revista Geocrítica (Versão resumida). Barcelona, 2007. Disponível em: <http://www.ub.es/geocrit/9porto/thomaz.htm>.

WITTMAN, Hannah. Food Sovereignty: a new rights framework for food and nature?. Nova lorque: Environment and Society; Berghahn Journals, 2011. p. 87-105.

WOORTMANN, Klaas. Com parente não se negoceia: o campesinato como ordem moral. Anuário antropológico, Rio de Janeiro: Tempo Brasileiro, n. 87, p. 11-73, 1990. 